\title{
Loop-Type Ground Radiation Antenna for a C-Shaped Ground Plane
}

\author{
Hongkoo Lee $\cdot$ Zeeshan Zahid · Hyeongdong Kim*
}

\begin{abstract}
In this study, optimum locations for a loop-type ground radiation antenna are evaluated for C-shaped ground planes of two different sizes. To achieve good radiation performance, the antenna needs to be located such that it couples with the dominant current mode of the ground plane. Antenna locations are proposed using the characteristic mode analysis of the ground planes. The measured bandwidths of the antennas at the proposed locations have more than twice the bandwidths of the cases in which the antennas are coupled with nondominant modes. The operating frequency of the antennas is $2.45 \mathrm{GHz}$.
\end{abstract}

Key Words: Characteristic Mode, Ground Radiation Antenna, Radiation Efficiency.

\section{INTRODUCTION}

The increasing market demand for Internet of Things (IoT) devices has emphasized the need for high-performance antennas for small devices. The performance of an electrically small antenna is determined by its physical size [1]. To design a highperformance antenna on a small ground plane, the antenna should be effectively coupled with the dominant characteristic mode of the ground plane. The loop-type ground radiation antenna (GradiAnt) is a promising option for mobile devices [2, 3]. Previous literature mainly focused on rectangular-shaped ground planes in which the GradiAnt is coupled with the firstorder mode. These antennas show good performance for a discontinuous square ring-shaped ground plane [4] in which the dominant mode is the second-order mode. The characteristic mode analysis of various ground plane shapes has been employed in efficient antenna designs [5, 6]. However, the application of the characteristic mode analysis in high-performance GradiAnt design still needs more attention.
In this study, the optimum location for a loop-type GradiAnt is evaluated for a C-shaped ground plane using the characteristic mode analysis. To demonstrate this technique, the locations of the GradiAnt are analyzed for two different C-shaped ground plane sizes. The effect of different antenna locations on the bandwidth and efficiency of the antenna is observed. The antenna location, where it effectively couples with the dominant ground mode, performs significantly better than the other location, where the antenna is coupled with the non-dominant mode. The simulation is conducted using a full wave simulator, and measured data are obtained in a $6 \mathrm{~m} \times 3 \mathrm{~m} \times 3 \mathrm{~m}$ threedimensional cellular telecommunications and Internet association over the air chamber.

\section{ANTENNA DESIGN AND OPERATING MECHANISM}

The GradiAnt consists of a rectangular clearance $4 \mathrm{~mm} \times 7$ $\mathrm{mm}$ in size. The feeding loop contains the feeding capacitor (Cf). The resonance capacitor $(\mathrm{Cr})$ is used to control the operat-

Manuscript received November 29, 2017 ; Revised March 22, 2018 ; Accepted September 19, 2018. (ID No. 20171129-069J)

Department of Electronics and Computer Engineering, Hanyang University, Seoul, Korea.

"Corresponding Author: Hyeongdong Kim (e-mail: hdkim@hanyang.ac.kr)

This is an Open-Access article distributed under the terms of the Creative Commons Attribution Non-Commercial License (http://creativecommons.org/licenses/by-nc/4.0) which permits unrestricted non-commercial use, distribution, and reproduction in any medium, provided the original work is properly cited.

(c) Copyright The Korean Institute of Electromagnetic Engineering and Science. All Rights Reserved. 
ing frequency of the antenna. Flame Retardant Type-4 (FR-4) $\left(\varepsilon_{r}=4.4, \tan \delta=0.02\right)$ with $1 \mathrm{~mm}$ thickness is used as a substrate material. Two $\mathrm{C}$-shaped ground plane sizes are considered. The smaller C-shaped ground plane is $30 \mathrm{~mm} \times 50 \mathrm{~mm}$ in size with a $15 \mathrm{~mm} \times 20 \mathrm{~mm}$ empty space at the right edge. The larger C-shaped ground plane is $48 \mathrm{~mm} \times 80 \mathrm{~mm}$ in size with a $24 \mathrm{~mm} \times 32 \mathrm{~mm}$ empty space at the right edge. The geometries of the GradiAnt and the ground planes are shown in Fig. 1. The thickness of the patterns is $0.5 \mathrm{~mm}$. Two GradiAnt locations on the ground plane are evaluated using the characteristic modes of the ground planes. One of the locations (P1) is the middle of the right edge of the ground plane, as shown in Fig. 1(a), and the other location (P2) is the middle of the left edge of the ground plane, as shown in Fig. 1(b).

The GradiAnt behaves as a magnetic coupler, and its radiation performance is attributed to its coupling with the ground plane. Based on the theory of characteristic modes, the total current $\mathrm{J}$ on the conducting body can be obtained through the following equation:

$$
\mathrm{J}=\sum_{n} \frac{\iiint\left(E_{i} \cdot J_{n}\right) d \tau}{1+j \lambda_{n}} E_{n},
$$

where $\iiint\left(E_{i} \cdot J_{n}\right) d \tau$ is the coupling between the impressed field $E_{i}$ and modal current $J_{n}$, and $\lambda_{n}$ is the eigenvalue associated with the $n^{\text {th }}$ characteristic current mode. $\lambda_{n}$ is closely related to the resonance frequency and the radiation performance. The coupling becomes maximum at resonance, when $\lambda_{n}$ approaches zero, as the denominator term becomes the smallest. According to Eq. (1), maximum coupling will be achieved if the antenna is located at the maximum current of the dominant ground mode. Moreover, the characteristic mode of the ground plane radiates effectively at resonance. Therefore, good radiation performance will be achieved if the antenna is coupled with the characteristic mode of the ground plane that is resonantly close to the operating frequency. The performance of the antenna at locations P1 and P2 is compared for both ground sizes. The characteristic modes of both ground planes are analyzed in a full wave simulator, and the eigenvalues of the firstand second-order modes of both ground planes are presented in Fig. 2. The resonant frequency of the first-order mode is 1.95 $\mathrm{GHz}$ at position 1 (P1), and it is close to the operating frequency of the antenna $(2.4-2.5 \mathrm{GHz})$, making the denominator term of Eq. (1) small. The resonant frequency of the secondorder mode is $4.79 \mathrm{GHz}$, which is far from the operating frequency of the antenna at position 2 (P2), thus making the denominator term of Eq. (1) large and the numerator term of Eq. (1) maximum. The performance of the antenna, coupled with the first- and second-order modes, is predicted on the basis of Eq. (1). According to this equation, the coupling of the antenna with the first-order mode is higher than that with the second order mode. Therefore, on the small $\mathrm{C}$-shaped ground plane,

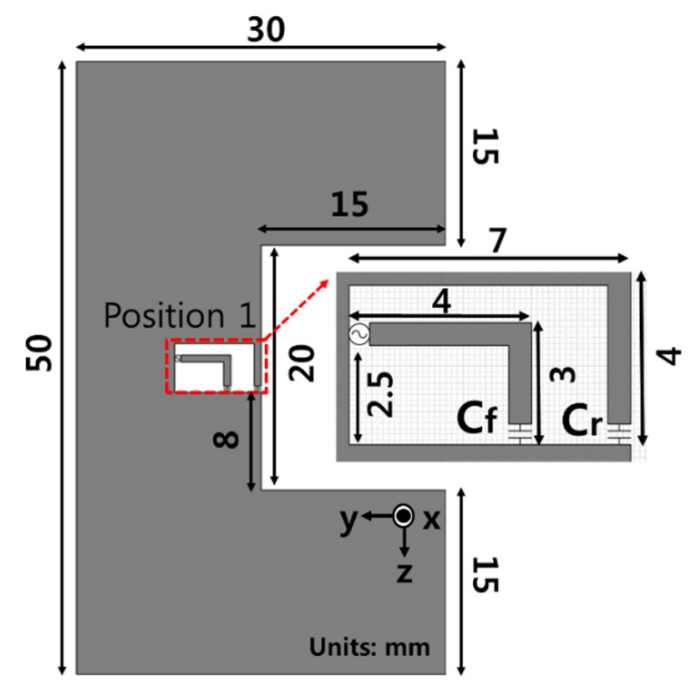

(a)

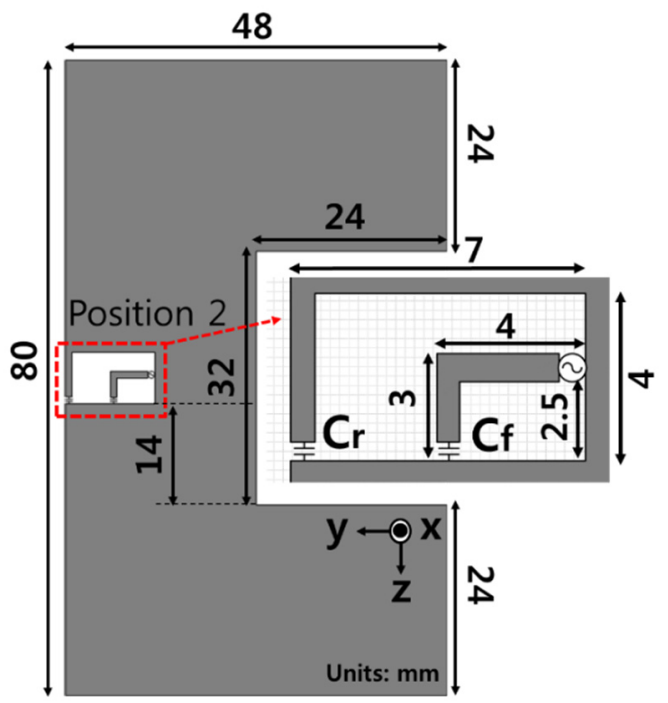

(b)

Fig. 1. Configuration of the proposed antenna on (a) a small and (b) a large $\mathrm{C}$-shaped ground plane.

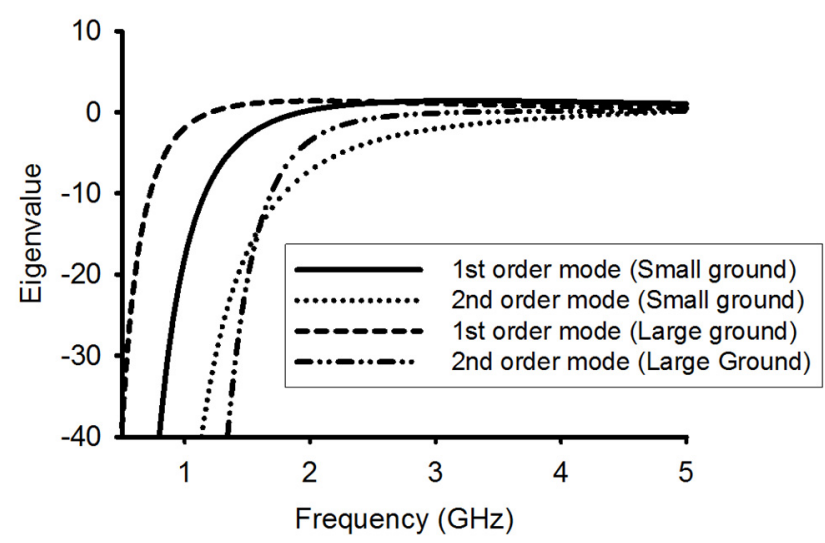

Fig. 2. Eigenvalues of the large and small $\mathrm{C}$-shaped ground planes.

the radiation performance of the antenna at location $\mathrm{P} 1$ is expected to be higher than that at $\mathrm{P} 2$. 


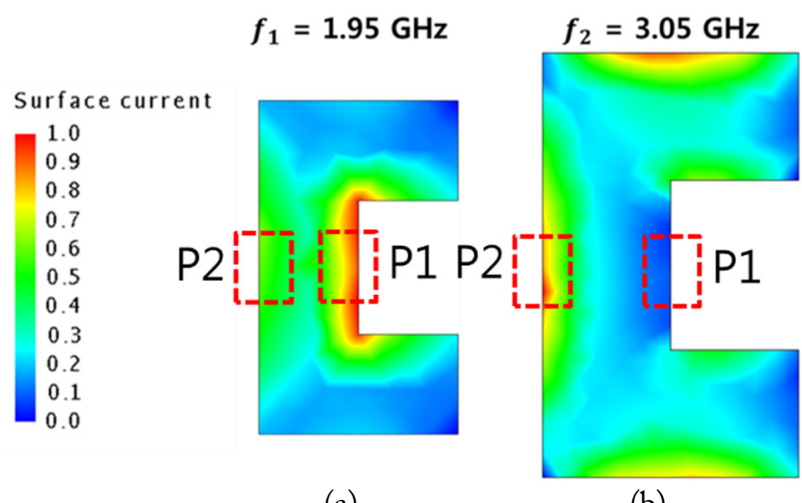

(a)

Fig. 3. Current distribution of the (a) small and (b) large C-shaped ground planes.

Conversely, at P1, the first-order mode of the larger ground plane is resonant at $1.23 \mathrm{GHz}$, which is far from the operating frequency of the antenna, thus making the denominator term of Eq. (1) large. At P2, the resonance frequency of the secondorder mode is at $3.05 \mathrm{GHz}$, which is closer to the operating frequency, thus making the denominator term of Eq. (1) small. Therefore, on the large $\mathrm{C}$-shaped ground plane, the radiation performance of the antenna at $\mathrm{P} 2$ is expected to be higher than that at $\mathrm{P} 1$.

To improve the radiation performance of the antenna, increasing the numerator term of Eq. (1) is important, and the location of the antenna is a crucial factor in determining the coupling. Therefore, the current distribution is analyzed to determine the position of the antennas. Fig. 3 shows the current distribution of the small and large $\mathrm{C}$-shaped ground planes. The optimum locations for the antennas are decided on the basis of the reaction theorem, which has the characteristic of the current maximum [7].

\section{SIMULATION AND EXPERIMENTAL RESULTS}

To verify the performance at the proposed locations on the $\mathrm{C}$-shaped ground planes, the designs are simulated and fabricated for measurement. The simulated and measured results are illustrated in Figs. 4 and 5.

Fig. 4 shows the results of the antenna on the small C-shaped ground plane. The simulated impedance bandwidth of the antenna at $\mathrm{P} 1$ is $470 \mathrm{MHz}(2,260-2,730 \mathrm{MHz})$ and that at $\mathrm{P} 2$ is $230 \mathrm{MHz}(2,330-2,560 \mathrm{MHz})$. The measured bandwidth of the antenna at $\mathrm{P} 1$ is $438 \mathrm{MHz}(2,303-2,741 \mathrm{MHz})$ and that at $\mathrm{P} 2$ is $175 \mathrm{MHz}(2,377-2,552 \mathrm{MHz})$. The measured results reveal that the bandwidth of the antenna at $\mathrm{P} 1$ is 2.5 times more than that at P2.

Fig. 5 shows the results of the antenna on the large $\mathrm{C}$-shaped ground plane. The simulated impedance bandwidth of the antenna at $\mathrm{P} 1$ is $120 \mathrm{MHz}(2,410-2,530 \mathrm{MHz})$ and that $\mathrm{P} 2$ is

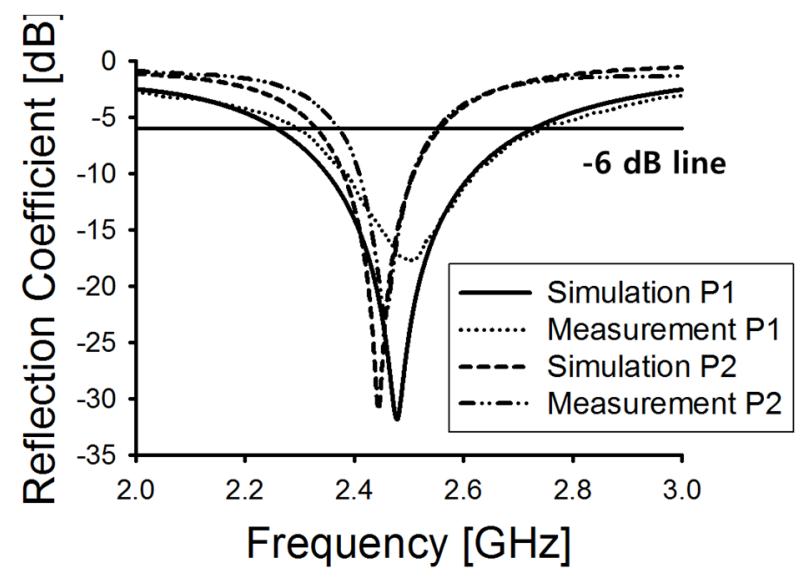

Fig. 4. Return loss characteristics of the small C-shaped ground plane.

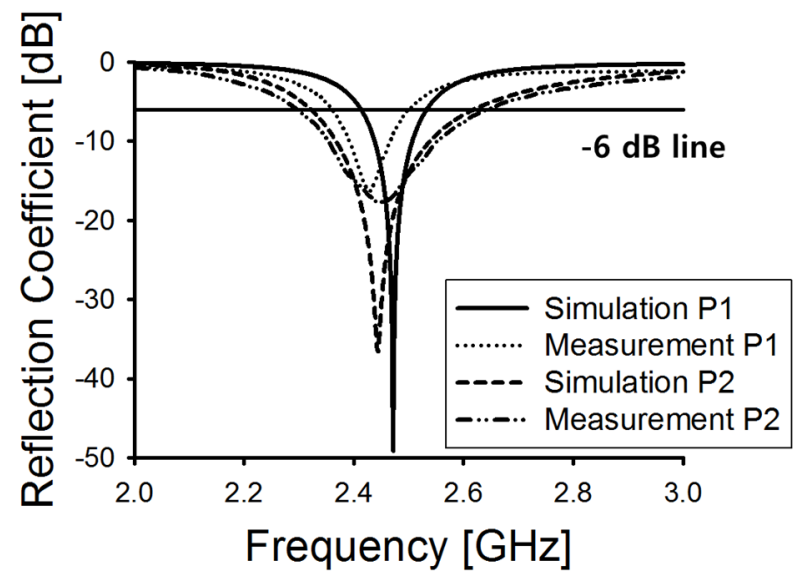

Fig. 5. Return loss characteristics of the large C-shaped ground plane.

$300 \mathrm{MHz}(2,320-2,620 \mathrm{MHz})$. The measured bandwidth of the antenna at $\mathrm{P} 1$ is $139 \mathrm{MHz}(2,361-2,500 \mathrm{MHz})$ and that at $\mathrm{P} 2$ is $352 \mathrm{MHz}(2,293-2,645 \mathrm{MHz})$. In this case, again the measured bandwidth of the antenna at $\mathrm{P} 2$ is approximately 2.5 times more than that at P1. Table 1 shows the measured and simulated efficiencies of the antennas. The measured and the simulated total radiation efficiencies of the antennas at $\mathrm{P} 1$ and $\mathrm{P} 2$ on the small C-shaped ground plane are $90.15 \%, 78.04 \%$, $88.65 \%$, and $80.00 \%$, respectively. On the larger C-shaped ground plane, the measured and the simulated efficiencies at P1 and $\mathrm{P} 2$ are $76.52 \%, 87.97 \%, 68.30 \%$, and $83.51 \%$ respectively. The measured and the simulated results indicate a significant

Table 1. Measured and simulated total radiation efficiencies of the antennas at P1 and P2 (unit: \%)

\begin{tabular}{cccccc}
\hline \multirow{2}{*}{$\begin{array}{c}\text { Ground } \\
\text { size }\end{array}$} & \multicolumn{2}{c}{ Position 1 } & & \multicolumn{2}{c}{ Position 2 } \\
\cline { 2 - 3 } \cline { 5 - 6 } & Measured & Simulated & & Measured & Simulated \\
\hline Small & 90.15 & 88.65 & & 78.04 & 80.00 \\
Large & 76.52 & 68.30 & & 87.97 & 83.51 \\
\hline
\end{tabular}


difference depending on the position of the antenna. This significant advantage in bandwidth and radiation efficiency verifies the suitability of the proposed antenna locations on the ground planes.

Fig. 6 shows the peak gain of the small and large $\mathrm{C}$-shaped ground planes at P1 and P2. For the small ground plane, the average peak gain is higher at $\mathrm{P} 1$, and for the large ground, the average peak gain is also higher at $\mathrm{P} 1$. However, the radiation efficiency of the large ground plane is higher at P2 because of the lower directivity.

The measured radiation pattern of the small ground plane at P1 is illustrated in Fig. 7, and the measured radiation pattern of the large ground plane at P2 is presented in Fig. 8. The radiation pattern of the antenna placed at $\mathrm{P} 1$ in the case of the small ground plane and that placed at P2 in the case of large ground plane are illustrated because they have better radiation performance. Both antennas show omni-directional radiation patterns.

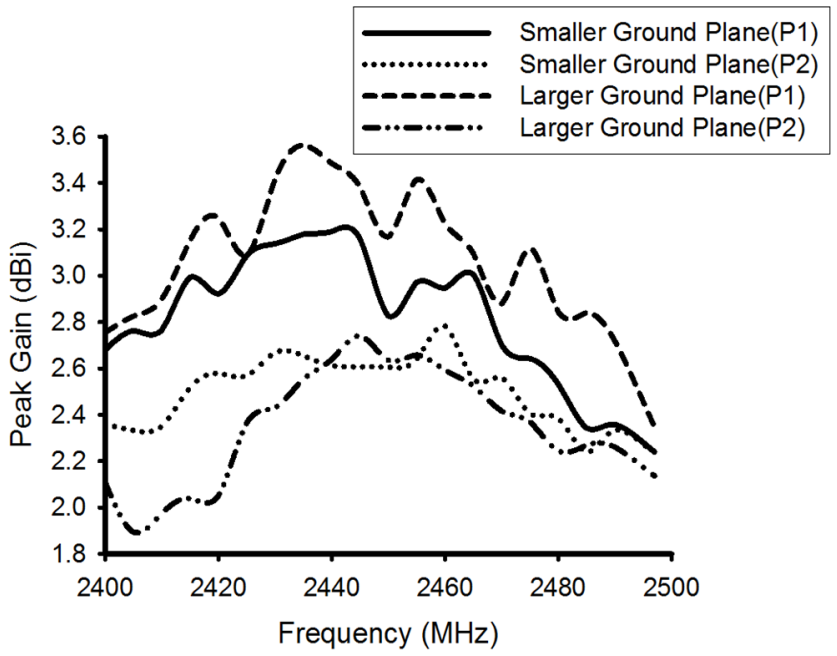

Fig. 6. Peak gain of the small and large $\mathrm{C}$-shaped ground planes at $\mathrm{P} 1$ and $\mathrm{P} 2$.

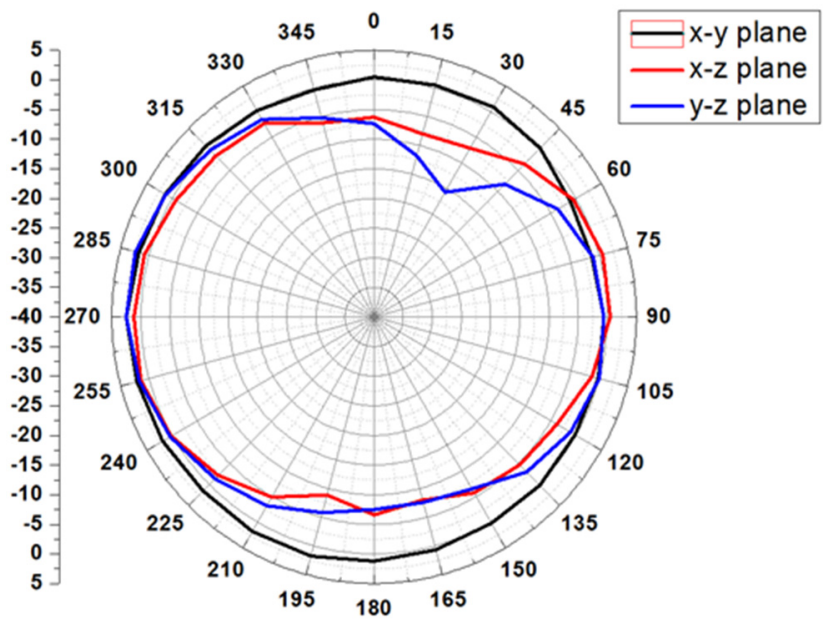

Fig. 7. Measured radiation pattern of the small ground plane at P1.

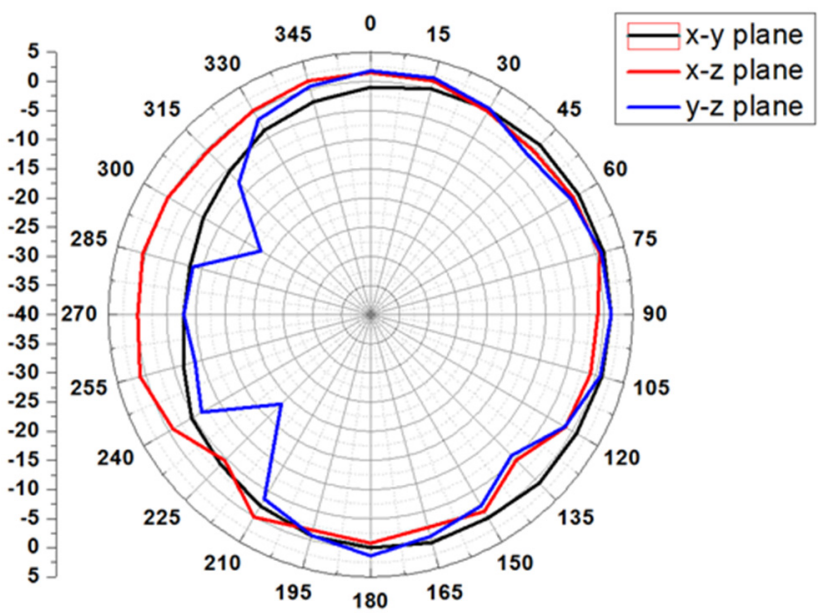

Fig. 8. Measured radiation pattern of the large ground plane at P2.

\section{CONCLUSION}

In this study, the optimum location for a loop-type ground radiation antenna was proposed for $\mathrm{C}$-shaped ground planes using the characteristic mode analysis. The simulations and measurements demonstrated that the antenna showed significantly better performance when located at the current maximum of the dominant mode of the ground plane. This analysis can be applied to small IoT devices to enhance the performance of the antenna.

This work was supported by the National Research Foundation of Korea grant funded by the Korean government (MSIP) (No. 2015R1A2A2A15055109).

\section{REFERENCES}

[1] J. S. McLean, "A re-examination of the fundamental limits on the radiation $\mathrm{Q}$ of electrically small antenna," IEEE Transactions on Antennas and Propagation, vol. 44, no. 5, pp. 672-676, 1996.

[2] Y. Liu, X. Lu, H. Jang, H. Choi, K. Jung, and H. Kim, "Loop-type ground radiation antenna using resonated loop feeding, intended for mobile devices," Electronics Letters, vol. 47, no. 7, pp. 426-427, 2011.

[3] O. Cho, H. Choi, and H. Kim, "Loop-type ground radiation antenna using capacitor," Electronics Letters, vol. 47, no. 1, pp. 11-12, 2011.

[4] Z. Zahid and H. Kim, "Loop-type ground radiation antenna for discontinuous ring-shaped ground plane," Electronics Letters, vol. 53, no. 12, pp. 760-762, 2017.

[5] M. Cabedo-Fabres, E. Antonino-Daviu, A. Valero-Nogueira, and M. F. Bataller, "Theory of characteristic modes revisited: a contribution to the design of the antennas for 
modern applications," IEEE Transactions on Antennas and Propagation Magazine, vol. 49, no. 5, pp. 52-68, 2007.

[6] I. Szini, A. Tatomirescu, and G. F. Pedersen, "On small terminal MIMO antennas, harmonizing characteristic modes

\section{Hongkoo Lee}

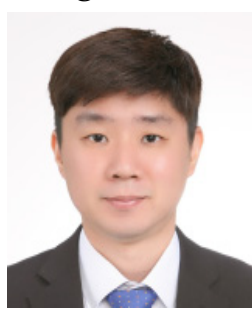

received his B.S., M.S., and Ph.D. degrees in electrical engineering from the Department of Electronics and Computer Engineering, Hanyang University, Seoul, Republic of Korea, in 2012, 2014, and 2018, respectively. He is currently working as a researcher at Samsung Electronics. His research interest is mobile antenna using the characteristic mode analysis.

\section{Zeeshan Zahid}

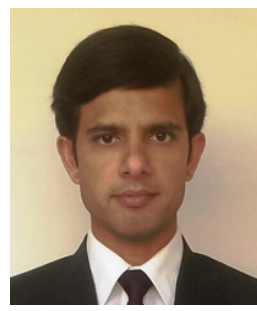

received his M.S. degree in electronics from Quaidi-Azam University, Islamabad, Pakistan in 2006. He joined the National University of Sciences and Technology (NUST) as a lecturer and was promoted to assistant professor in 2012. He received the "Best Teacher of the Year" award in 2012. He received his Ph.D. degree from Hanyang University, South Korea, in 2017. Currently, he serves as an assistant professor at the Department of Electrical Engineering, College of Signals, NUST, Rawalpindi campus. His main research interests include highefficiency antenna design for mobile devices, circularly polarized antennas for mobile devices, MIMO antennas, and ultra-wide band antennas. with ground plane Geometry," IEEE Transactions on Antennas and Propagation, vol. 63, no. 4, pp. 1487-1497, 2015.

[7] R. F. Harrington, Time-Harmonic Electromagnetic Fields. New York, NY: Wiley, 2001.

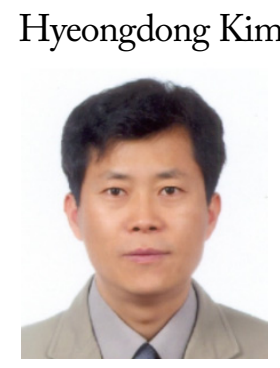

(S'89-M'91)

was born in Kwang-ju, Republic of Korea. He received his B.S. and M.S. degrees from the Seoul National University, Seoul, Republic of Korea, in 1984 and 1986, respectively, and his Ph.D. degree from the University of Texas at Austin, in 1992. From May 1992 to February 1993, he was a PostDoctoral Fellow at the University of Texas at Austin. In 1993, he worked as a professor at the Department of Electrical and Computer Engineering, Hanyang University, Seoul, Republic of Korea. His current research interest are various antenna theories and designs based on ground characteristic mode analysis, namely, wideband, high-efficiency, circular polarization, MIMO, and high-sensitivity antennas. 